\title{
LAS FUENTES TEÓRICO-METODOLÓGICAS DE LA CONSTRUCCIÓN DEL CONCEPTO DE DEPENDENCIA
}

M. Gabriela Vázquez Olivera*

RESUMEN: La construcción de la dependencia como categoría de análisis es fruto de intensos debates en el seno de la CEPAL y de las corrientes marxistas a lo largo de los años cincuenta, sesenta e inicio de los setenta del siglo veinte; discusiones y propuestas que implicaron una serie de rupturas teórico-metodológicas con el pensamiento social hasta entonces imperante y que abrieron un nuevo horizonte de visibilidad que permitió abordar los problemas específicos de nuestra región en el marco del capitalismo como sistema mundial, con la mirada puesta en la búsqueda de alternativas más dignas y más justas para América Latina. Desde la perspectiva de la construcción del conocimiento, el proceso que dio lugar a la formulación de la dependencia como herramienta de análisis constituye una conquista del pensamiento social latinoamericano, que hoy es necesario rescatar.

Palabras ClaVe: Especificidades, Historicidad, Horizonte de reflexión, Producción teórica, Desarrollo/subdesarrollo, Dependencia.

América Latina ha sido objeto de reflexión con una perspectiva crítica desde finales del siglo XIX y principios del XX. Entre los trabajos realizados desde y para América Latina destacan, en primer término, los escritos de José Martí y posteriormente, como parte de la búsqueda de hacer una aplicación creadora del marxismo a nuestra realidad específica, los aportes del cubano José Antonio Mella y, especialmente, los trabajos del peruano José Carlos Mariátegui. Pero sería hasta mediados del siglo pasado que se construyeron corrientes teóricas estructuradas y originales del pensamiento social latinoamericano.

* Facultad de Ciencias Políticas y Sociales, UNAM (gvazquez@sds.df.gob.mx). 
Haciendo un somero recuento histórico, es posible identificar como un periodo de intensa y fructífera producción teórica el que inicia en la década de los años cincuenta y se extiende hasta principios de los años setenta del siglo XX. Los factores que hicieron posible ese excepcional periodo para las ciencias sociales latinoamericanas tienen que ver con las preguntas que el momento histórico planteó y con las disputas políticas que tuvieron lugar en aquella época en torno a proyectos de nación alternativos con posibilidades de cristalización para los países latinoamericanos.

La discusión giró entonces alrededor del tema del desarrollo y los investigadores que participaron en ella lo hicieron con la mirada puesta en la construcción de proyectos de futuro para nuestros países. Los intensos debates hicieron posible plantear la historia de la región en términos de una historia propia y contribuyeron a ubicar a América Latina como un problema teórico que reclama conceptos y categorías para el abordaje de su realidad.

Inicialmente funcionaron como eje articulador de las elaboraciones teóricas — realizadas desde esa perspectiva - las propuestas y conceptos surgidos en el seno de la Comisión Económica para América Latina (CEPAL) durante la década de los años cincuenta; formulaciones que implicaron una serie de rupturas teórico-metodológicas con el pensamiento social hasta entonces imperante y que abrieron un nuevo horizonte de visibilidad para el análisis de la realidad latinoamericana.

Los planteamientos iniciales de la CEPAL se tradujeron en una serie de lineamientos de política económica tendientes a impulsar el desarrollo de América Latina vía la industrialización sustitutiva de importaciones; mismos que fueron aplicados en términos generales por la mayoría de los países de la región. Al iniciarse la década de los sesenta el debate avanzó en el plano teórico producto de los problemas sociales derivados del modelo de desarrollo propuesto y con los aportes de una corriente marxista crítica que emergió alentada por las interrogantes abiertas con el triunfo de la Revolución cubana.

La noción de dependencia y su posterior construcción como categoría de análisis constituyen el aporte final más creativo de aquellos 
debates. Desde la perspectiva de la dependencia fue reescrita la historia de nuestra región, se estudiaron los problemas de la industrialización, del campo, de la marginalidad; se discutió acerca de la idea de nación, de Estado, de clases sociales y de las posibilidades de transformación revolucionaria de nuestros países; se elaboraron reflexiones sobre la educación, la idea de raza y los problemas étnicos; se profundizó el debate en torno a la teología y la filosofía de la liberación, etc.; generándose una corriente de pensamiento crítico cuya preocupación central era la construcción de proyectos alternativos más justos y más dignos para los pueblos latinoamericanos.

Para estudiar la dependencia desde la perspectiva de la construcción del conocimiento, entendido éste como un proceso histórico, es necesario un recuento de los puntos de partida, las continuidades y rupturas teóricas del pensamiento social latinoamericano que posibilitaron su formulación como categoría de análisis. Esto será el asunto de este trabajo, con la intención de avanzar después en el análisis de la construcción de la dependencia como instrumento analítico, en sus formulaciones más acabadas.

\section{EL PENSAMIENTO DE LA CEPAL}

Rastrear las fuentes teórico-metodológicas de la dependencia como categoría de análisis conlleva necesariamente a revisar las propuestas teóricas surgidas en el seno de la CEPAL, especialmente si se consideran las posibilidades de análisis que abrió el pensamiento cepalino de la década de los cincuenta y principios de los sesenta, así como las formulaciones que posibilitaron la emergencia del concepto de dependencia en el seno de esa institución.

El punto de partida del pensamiento de la CEPAL: la teoría del desarrollo

En junio de 1948 fue creada la Comisión Económica para América Latina (CEPAL) como parte del establecimiento en el seno de las Naciones 
Unidas de organismos regionales destinados al estudio y elaboración de propuestas para superar los problemas del capitalismo atrasado.

Después de tres décadas de crisis en las relaciones internacionales (Primera Guerra Mundial, desajustes en los años veinte en Europa, depresión de los años treinta y Segunda Guerra Mundial), el tema del desarrollo se había convertido en una de las preocupaciones centrales tanto en el medio académico como en las instancias generadoras de política económica en el ámbito internacional. El problema se potenció con los procesos de descolonización que siguieron a la Segunda Guerra Mundial y la masiva incorporación al mercado mundial de una serie de naciones pobres y atrasadas, la reconstrucción europea, el crecimiento de los países socialistas y la indiscutible hegemonía alcanzada por Estados Unidos. Era necesario encontrar explicaciones y justificaciones ante las naciones pobres de las razones de su atraso y, al mismo tiempo, ofrecerles un camino de solución. Esa fue la preocupación a la que buscó dar respuesta la teoría del desarrollo. ${ }^{1}$

El elemento central de la teoría del desarrollo de Rostov era la idea del desarrollo como un continuиm y del subdesarrollo como una etapa previa al desarrollo pleno, accesible a todos los países que se empeñaran en crear las condiciones adecuadas; es decir, que se propusieran impulsar a su interior la modernización de la economía, la sociedad y las instituciones de acuerdo con los patrones vigentes en los países capitalistas más desarrollados. Los países atrasados podían alcanzar el desa-

${ }^{1}$ En la década de los cincuenta la teoría del desarrollo alcanzó su punto más radical y, al mismo tiempo, más divulgado, con la obra de W. Rostov quien definió a todas las sociedades precapitalistas como tradicionales y trató de demostrar que el inicio del desarrollo en esas sociedades no dependía de un Estado revolucionario, como había sucedido en URSS, y sí de un conjunto de medidas económicas tomadas por cualquier Estado nacional que asumiese una ideología desarrollista. Véase Theotonio Dos Santos, "La teoría de la dependencia. Un balance histórico y teórico", en Los Retos de la Globalización. Ensayos en Homenaje a Theotonio Dos Santos, Caracas, UNESCO, 1998. 
rrollo a través de la adopción de normas de conducta, actitudes y valores identificados con la racionalidad económica moderna, caracterizada por la búsqueda de la productividad máxima, la generación de ganancias y la creación de inversiones que llevasen a la acumulación permanente de las riquezas por parte de los individuos y, en consecuencia, de cada sociedad nacional.

Desde esa perspectiva, se reconocía que el paso hacia la modernización en los países atrasados, además de traer consigo la posibilidad de tensiones y crisis, se manifestaría durante cierto tiempo mediante una situación de dualismo estructural, que opondría un sector moderno al sector tradicional de la sociedad en cuestión. Por ello, la teoría del desarrollo buscó localizar los obstáculos a la plena implantación de la modernidad y definir los instrumentos de intervención, capaces de alcanzar los resultados deseados. ${ }^{2}$ Esa era la tarea central que debían realizar las Comisiones Económicas para Europa, para Asia y el Lejano Oriente, y la Comisión Económica para América Latina, creadas entre 1946 y 1948 .

La CEPAL no rehuyó la misión que le había sido confiada, sin embargo, lejos de limitarse a la mera difusión de la teoría del desarrollo asumió un papel crítico y creador al abordar los problemas concretos de la realidad latinoamericana, de tal manera que las elaboraciones teóricas surgidas en su seno implicaron una serie de rupturas teóricas con la teoría económica clásica y con el marco conceptual que supuestamente iba a guiar sus análisis y acciones.

[...] la CEPAL, al constituirse, se vincula a la realidad interna de América Latina y expresa las contradicciones de clase que la caracterizan, incluso las contradicciones interburguesas. [...] Ello hará que la CEPAL, partiendo de la teoría del desarrollo, en los términos que había sido formulada en los grandes centros, introduzca en ella cambios que representarán su con-

${ }^{2}$ Corresponden a esta forma de pensamiento los trabajos sobre América Latina elaborados por José Medina Echavarría y Gino Germani, en su primera época. 
tribución propia, original, y que harán del desarrollismo latinoamericano un producto sí, pero no un simple calco de la teoría del desarrollo. ${ }^{3}$

\section{Los horizontes de reflexión que abrió el pensamiento cepalino}

Desde su creación la CEPAL aglutinó a un conjunto de brillantes investigadores entre los que destacan Raúl Prebisch (quien asumió la dirección del organismo en 1949), Celso Furtado, Juan Noyola y Anibal Pinto. La tarea de reflexionar sobre América Latina y su desarrollo encomendada al organismo, llevó a estos investigadores al cuestionamiento de las visiones prevalecientes en la materia y a la necesidad de abordar el trabajo desde una perspectiva que buscaba captar y explicar las especificidades de la realidad concreta latinoamericana.

Los trabajos realizados en el seno de la CEPAL no fueron concebidos explícitamente con el propósito de construir una teoría económica, se trató, como afirma Raúl Prebisch, de un conjunto de "ideas que fueron brotando en nosotros a medida que abordamos problemas concretos de la realidad latinoamericana". El programa de reflexión e investigación que guió el conjunto de elaboraciones teóricas realizadas en el seno de la CEPAL fue planteado por Prebisch en 1949 y se desprendía esencialmente del diagnóstico de la profunda transición que se observaba en las economías subdesarrolladas latinoamericanas que en aquellos años transitaban del modelo de acumulación primarioexportador (desarrollo "hacia fuera") hacia un patrón basado en la industrialización (desarrollo "hacia adentro").

Los diversos aportes se originan en el examen de problemas concretos, sean de toda el área o de algunas de las economías que la conforman. En torno a tales problemas se fueron articulando una serie de argumentos teóricos que buscaban explicar las causas de los mismos y,

${ }^{3}$ Ruy Mauro Marini, "La crisis del desarrollismo", en Ruy Mauro Marini y Márgara Millán [coords.], La teoría social latinoamericana. T. II Subdesarrollo y Dependencia, México, Ediciones el Caballito, 1994, p. 140. 
especialmente, fundamentar las propuestas de política económica que se consideraron adecuadas para resolverlos. A pesar de las deficiencias que podría implicar ese método que Octavio Rodríguez califica de "pragmático", el conjunto de las contribuciones cepalinas, afirma el mismo Rodríguez, posee un desenvolvimiento analítico que presenta una unidad de pensamiento y una coherencia interna acerca de lo que se ha llamado la concepción originaria de la CEPAL, formulada durante los primeros años de la década de los cincuenta, que permite hablar de ellas como "el esbozo de una teoría de la economía periférica o, en otros términos, el esbozo de una teoría del subdesarrollo". ${ }^{4}$

La concepción originaria del pensamiento de la CEPAL abrió un nuevo horizonte de reflexión y sentó las bases teórico-metodológicas desde las cuales se hizo posible analizar los problemas del desarrollo latinoamericano a partir de su propia especificidad histórica y con base en ello buscar caminos y soluciones propias para nuestra región. La recapitulación de los planteamientos que constituyen los ejes de las elaboraciones teóricas realizadas en el seno de la CEPAL durante la década de los cincuenta, permite sustentar esa afirmación.

\section{a) América Latina como problema teórico}

$\mathrm{Al}$ hablar de un nuevo horizonte de reflexión me refiero, en primer término, a que el pensamiento cepalino al centrar su atención en las problemáticas de los países latinoamericanos, específicamente en el estudio de las tendencias económicas de mediano y largo plazo del capitalismo subdesarrollado de la región, abrió el camino para ubicar a América Latina como un problema teórico, esto es, como un sujeto histórico cuyo estudio reclama conceptos y cuerpos teóricos específicos.

En el desarrollo de sus investigaciones los teóricos cepalinos fueron descubriendo las particularidades que la región presentaba. Espe-

${ }^{4}$ Octavio Rodríguez, La teoría del subdesarrollo de la CEPAL, México, Siglo XXI, 1980 . 
cificidades vinculadas a los mayores niveles de desarrollo del capitalismo en América Latina respecto de otras regiones atrasadas, y en particular, al hecho de que los procesos de industrialización, que ya se estaban dando en buena parte de nuestros países, no seguían el mismo camino que había tenido lugar en los países desarrollados.

La teoría del desarrollo, al surgir de la idea de desarrollo y subdesarrollo como momentos constitutivos de una misma realidad (la economía capitalista industrializada), centraba su atención en la diferenciación de los países desarrollados y subdesarrollados mediante criterios cuantitativos que permitieran ubicar a una economía en éste o aquel grado de una escala evolutiva, de tal manera que el subdesarrollo se definía básicamente a través de una serie de indicadores: producto real, grado de industrialización, ingreso per cápita, índices de alfabetización y escolaridad, tasas de mortalidad, esperanza de vida, etc., destinados a clasificar a las economías del sistema mundial y a registrar su avance en la senda del desarrollo. Planteamiento que además de no corresponder a la realidad latinoamericana, en el plano metodológico limitaba el análisis esencialmente a estudios descriptivos. ${ }^{5}$

De ahí que para los teóricos de la CEPAL la tarea a desempeñar no era comparar el subdesarrollo latinoamericano con la historia pretérita de las economías centrales, ni evaluar en esos términos el grado de desarrollo alcanzado, sino por el contrario era prioritario identificar las singularidades históricas de la especificidad del desarrollo de América Latina en el que sin duda había secuencias y resultados distintos de los que se dieron en los países desarrollados.

Desde sus primeros escritos de 1949 Prebisch alertó sobre las particularidades del proceso de crecimiento de los países de América Latina y exigió un espacio analítico propio para estudiarla:

una de las fallas más ingentes de que adolece la teoría económica general, contemplada desde la periferia, es su falso sentido de universalidad [...]

${ }^{5}$ Véase Marini, op. cit. 
No hay que confundir el conocimiento reflexivo de lo ajeno con una sujeción mental a las ideas ajenas, de las que muy lentamente estamos aprendiendo a liberarnos. ${ }^{6}$

Otros investigadores enfatizaron también la importancia de entender el subdesarrollo como un contexto histórico específico que exige una teorización propia, ya que, como afirmó unos años más tarde el brasileño Celso Furtado:

El subdesarrollo no constituye una etapa necesaria del proceso de formación de las economías capitalistas modernas. Es en sí, un proceso particular, resultante de la penetración de las empresas capitalistas modernas en las estructuras arcaicas. El fenómeno del subdesarrollo se presenta en formas variadas y en distintas etapas, [...] Como fenómeno específico que es, el subdesarrollo requiere un esfuerzo de teorización autónomo. La falta de ese esfuerzo ha movido a muchos economistas a explicar, por analogía con la experiencia de las economías desarrolladas, problemas que sólo pueden ser debidamente planteados con base en una comprensión adecuada del fenómeno del subdesarrollo. ${ }^{7}$

Los trabajos de la CEPAL, producto de ese esfuerzo de teorización autónomo, rompieron con los estudios meramente descriptivos y buscaron explicar las características propias del subdesarrollo latinoamericano recurriendo principalmente al análisis de la dinámica de la economía internacional y de las relaciones que allí se desenvuelven entre las economías nacionales. Con ello, por un lado se señaló la necesidad de realizar el estudio de la realidad latinoamericana en el contexto de la economía internacional, aspecto que sería más tarde retomado por los teóricos de la dependencia como punto de partida analítico (el capitalismo como sistema mundial), y por otro, inclinó los análisis cepalinos hacia el estudio de los factores externos que incidían en el subdesarro-

${ }^{6}$ Ricardo Bielschowsky, "Cincuenta años del pensamiento de la CEPAL: una reseña", en Cincuenta años del pensamiento en la CEPAL. Textos seleccionados, Santiago de Chile, CEPAL/FCE, 1998, p. 16.

7 Celso Furtado, "Desarrollo y subdesarrollo", en ibid., pp. 240-241. 
1lo. El eje articulador de los análisis realizados fue la concepción de la economía internacional como un sistema centro-periferia.

b) El sistema centro-periferia

Tras la Segunda Guerra Mundial la visión del mundo como una unidad conformada por partes interdependientes ganó creciente fuerza. Esta percepción también cobró importancia en América Latina con la crisis del modelo primario exportador, afectado significativamente por los vaivenes de la economía internacional que provocó una importante caída de los precios de los bienes exportables de la región.

Durante los primeros años de la posguerra, bajo el liderazgo de la economía estadounidense, la visión de la interdependencia cristalizó en la creación de organismos que velarían por aspectos de política internacional (como la Organización de las Naciones Unidas), en pactos militares regionales (como la Organización del Tratado del Atlántico Norte) y en los organismos que buscaban poner orden en la economía internacional (Fondo Monetario Internacional y Banco Mundial). En ese contexto, para los teóricos cepalinos se hizo evidente que los problemas de América Latina reclamaban un marco de referencia que rebasara los límites geográficos de la región, mismo que no podía ser otro que el de la economía internacional, vista como unidad.

Inicialmente la atención se centró en las relaciones económicas internacionales, específicamente en el papel del progreso técnico y la distribución de sus frutos ya que, como afirmara Raúl Prebisch:

[...] los datos empíricos revelaban una desigualdad considerable entre los productores y exportadores de bienes manufacturados, por una parte, y los productores y exportadores de bienes primarios, por la otra. Traté de entender la naturaleza, las causas y la dinámica de esta desigualdad y estudié algunas de sus manifestaciones $[\ldots]^{8}$

${ }^{8}$ Raúl Prebisch, "Cinco etapas de mi pensamiento sobre el desarrollo", Comercio Exterior, vol. 37, núm. 5, México, mayo, 1987, p. 345. 
Ese análisis desembocó en la formulación de lo que constituiría el eje del pensamiento cepalino: la concepción del sistema centro-periferia.

Tratando de encontrar una explicación de estos fenómenos en aquellos años, hice especial hincapié en el hecho de que los países de la América Latina forman parte de un sistema de relaciones económicas internacionales que denominé el sistema "centro-periferia".

En el esquema centro-periferia la economía internacional se concibe como un sistema único, con dos polos: el centro y la periferia, cuyas estructuras productivas difieren en modo sustancial. Los centros son aquellas economías donde primero se desarrollaron las técnicas capitalistas de producción; la periferia, en cambio, está conformada por las economías cuya producción permanece inicialmente rezagada desde el punto de vista tecnológico y organizativo. Dicha concepción bipolar del sistema económico mundial define ciertas peculiaridades de la estructura productiva periférica: ésta se dice heterogénea, para indicar que existen actividades en las cuales la productividad del trabajo es elevada, y sectores en los que la misma es muy baja, debido al atraso tecnológico; además se la califica de especializada, en tanto la actividad exportadora se concentra en pocos bienes primarios, y en cuanto carece de muchos de los sectores existentes en aquellas economías modernas donde las técnicas capitalistas se difundieron con amplitud. Por contraste, la estructura productiva de los centros se considera homogénea y diversificada.

Sobre esa diferenciación de sus estructuras se asientan las distintas funciones de esos dos tipos de economía en el esquema tradicional de la división internacional del trabajo: la periferia obtiene de los centros una gama muy amplia de bienes, en especial productos manufacturados, en cambio, las importaciones que los centros realizan desde la periferia están constituidas fundamentalmente por alimentos y materias primas.

9 Ibid. 
En resumen, se concibe que centro y periferia forman un sistema único, cuya dinámica se caracteriza por la desigualdad entre los niveles de ingreso y las estructuras productivas de sus dos polos. Esa evolución bipolar se produce no sólo en la fase de desarrollo hacia afuera, sino también en la fase que le sigue, llamada de industrialización o de desarrollo hacia adentro.

Al hacer un recuento de las distintas etapas de su pensamiento, Prebisch resume la concepción del sistema centro-periferia de la siguiente manera:

Había en efecto, una "constelación económica" cuyo centro lo constituían los países industrializados favorecidos por esta posición — apoyada en su avance previo en materia de progreso técnico-, quienes organizaban el sistema en su conjunto para que sirviera a sus propios intereses. Los países productores y exportadores de materias primas estaban así conectados con el centro en función de sus recursos naturales, de modo que formaban una periferia vasta y heterogénea, incorporada en el sistema en forma y amplitud diferentes. ${ }^{10}$

El rezago de la estructura productiva de la periferia, que subsiste al entrar a la fase de industrialización, es lo que impide a la periferia generar progreso técnico, incorporarlo a la producción y elevar por esa vía la productividad del trabajo en medida similar a los centros. En el sistema centro-periferia existe pues una tendencia al desarrollo desigual de los dos polos que lo constituyen. Desigualdad creciente entre los niveles de ingreso real medio, por una parte y, por la otra, desigualdad en cuanto al grado de penetración y difusión del progreso técnico (homogeneidad) y en cuanto al grado de complementariedad intersectorial e integración de sus estructuras productivas (diversificación).

La concepción de la economía internacional como un sistema centro-periferia puso de manifiesto que, en efecto, los dos polos del sistema se encuentran interrelacionados, pero de manera asimétrica, por lo que

${ }^{10}$ Ibid., p. 346. 
la dinámica de la economía internacional implica una exagerada absorción de ingreso de la periferia por parte del centro y la tendencia a reproducir esa diferenciación con resultados negativos para la periferia.

Octavio Rodríguez señala que la formulación del sistema centroperiferia refleja claramente la naturaleza estructuralista de la concepción inicial de la CEPAL ya que:

[...] esa concepción privilegia las peculiaridades de la estructura productiva de la periferia, entre las que se destaca el nivel de productividad del trabajo de los distintos sectores productivos y el grado de complementariedad existente entre ellos; tales peculiaridades se establecen en ambos casos por contraposición con las que posee la estructura productiva de los centros, lo que implica que simultáneamente se está definiendo un sistema, el sistema centro-periferia; la desigualdad se considera inherente a su dinámica: las estructuras productivas de los polos se hacen más amplias y complejas pero las diferencias entre dichas estructuras (y entre los respectivos niveles de ingreso real medio) tienden a perdurar. ${ }^{11}$

Pero es necesario destacar que en la concepción cepalina, la diferenciación estructural de centros y periferia no implica que ésta permanezca aislada y en estado de atraso. Al contrario, se supone que en ambos modelos y fases los dos polos se interconectan y se condicionan recíprocamente, y que en cada uno de ellos van ocurriendo cambios estructurales. Así pues, los conceptos de centro y periferia no se definen con base en una diferenciación estática de sus estructuras productivas, sino que de alguna manera incorporan las ideas de interconexión y cambio estructural.

${ }^{11}$ Rodríguez, op. cit., p. 247. El mismo autor al ampliar su argumentación afirma que "la concepción del sistema centro-periferia muestra que su enfoque es compatible con definir estructura como 'las proporciones y relaciones que caracterizan a un conjunto económico localizado en el tiempo y en el espacio’ (F. Perroux); y sistema como un 'complejo coherente de estructuras'(J. Lhomme), siempre que se entienda que dicho concepto posee una connotación dinámica, esto es, que las estructuras se van transformando, y con ellas cambia el propio sistema (A.Marchal)", en ibid., p. 247. 
De acuerdo con Bielschowsky, el sistema centro-periferia, aunado a la inclinación cepalina por las tendencias históricas, dio forma al método histórico-estructuralista basado en el argumento de la condición periférica, que caracterizó las teorizaciones de la CEPAL. En el estudio realizado con motivo de la conmemoración de los cincuenta años del organismo, el autor señala:

La perspectiva estructuralista se instaló en el centro de los análisis, como consecuencia directa del objeto de reflexión que se proponía la institución [pero, a diferencia de lo ocurrido en otros casos] [...] en el análisis económico cepalino el estructuralismo es esencialmente un enfoque orientado por la búsqueda de relaciones diacrónicas, históricas y comparativas, que se presta más al método "inductivo" que a una "heurística positiva". De ahí provienen los fundamentos esenciales para la construcción teórica del análisis histórico comparativo de la CEPAL: las estructuras subdesarrolladas de la periferia latinoamericana condicionan — más que determinan — comportamientos específicos, de trayectorias desconocidas a priori. Por tal motivo, merecen y exigen estudios y análisis en los que la teoría económica con el sello de universalidad sólo puede emplearse con reservas, para poder incorporar esas especificidades históricas y regionales. ${ }^{12}$

No puede dejar de mencionarse que en el plano analítico el esquema centro-periferia presenta limitaciones especialmente derivadas de su base en los factores económicos, pues se dejó de lado la estructura social y el papel hegemónico de los centros (limitaciones que el propio Prebisch reconoció más tarde $)^{13}$ y que el énfasis en los factores externos

2 Bielschowsky, op. cit., p. 14.

${ }^{13} \mathrm{Al}$ referirse a lo que él denomina "la quinta etapa de mi pensamiento sobre los problemas de mi pensamiento económico", que ubica temporalmente al inicio de la década de los ochenta, Prebisch afirma que para empezar a construir realmente un sistema teórico: "era necesario llevar la perspectiva más allá de la mera teoría económica. En efecto, los factores económicos no pueden separarse de la estructura social. [...] Mi antiguo concepto de centro y periferia seguía siendo válido, pero debía enriquecerme mediante la introducción de algunas consecuencias muy importantes de la hegemonía de los centros." Prebisch, op. cit., p. 349. 
llevó a soslayar, al menos en esa primera etapa, los factores internos y las relaciones de clase que al interior de los países latinoamericanos favorecen la reproducción del subdesarrollo; aspectos fundamentales de los que posteriormente se buscó dar cuenta a través de la categoría de dependencia en sus diversas formulaciones.

Pero, sin dejar de reconocer esas limitaciones, es necesario destacar que la noción del sistema centro-periferia representó un avance significativo en la forma de abordaje de la problemática del desarrollo de América Latina.

El sistema centro-periferia, hizo posible percatarse de que las diferencias entre países desarrollados y subdesarrollados son más profundas y van mucho más allá de lo señalado por la teoría del desarrollo: el atraso y el subdesarrollo no son un momento previo al pleno desarrollo, sino resultado de una transferencia de recursos a favor del centro. Con ello, como señala Jaime Osorio:

Más allá de los límites que inicialmente el propio Prebisch le puso a estos términos, [...] la idea de centros y periferias tiende a abrir una caja de Pandora de la que aparecen visiones que ponen en entredicho la idea de economías diferenciables sólo por los estadios diversos de desarrollo, o que mantienen relaciones que sólo inciden en unas y en otras de manera tangencial. Por el contrario, tales economías se encuentran interrelacionadas $\mathrm{y}$, además, de manera asimétrica. ${ }^{14}$

Desde el punto de vista analítico, el sistema centro-periferia implicaba la necesidad no sólo de desarrollos teóricos que repararon sobre las especificidades del desarrollo latinoamericano en el marco del contexto de la economía internacional, sino también de la búsqueda de caminos propios, acordes con esas características.

Pero más aun, tras la noción de centros y periferias subyace la idea de que el atraso y el subdesarrollo son expresión de economías que su-

${ }^{14}$ Jaime Osorio, Fundamentos del análisis social. La realidad social y su conocimiento, México, UAM/FCE, p. 156. 
fren despojos, mientras el desarrollo es expresión de economías que han creado los instrumentos para despojar, idea que, de acuerdo con Marini, ${ }^{15}$ hace recordar algunas propuestas de la teoría del imperialismo y que fue retomada y ampliamente desarrollada por los teóricos marxistas de la dependencia.

c) El deterioro de los términos de intercambio

La tesis de la tendencia al deterioro de los términos de intercambio fue la fórmula central de las elaboraciones cepalinas para explicar esa transferencia de recursos de la periferia al centro. Con su formulación Prebisch y la CEPAL rompieron con los planteamientos de la teoría clásica sobre el comercio internacional y sus posibles efectos en materia de desarrollo.

La teoría clásica del comercio internacional basada en el principio de las ventajas comparativas, es decir, en la especialización de cada país en la producción de los bienes en que pueda lograr mayor productividad de acuerdo con sus recursos, afirma que dicho comercio termina por provocar una derrama de beneficios a todas las economías. Según esto, América Latina debía seguir especializándose en la producción de materias primas y alimentos, en tanto el mundo industrial debía hacerlo en bienes secundarios, y con ello, a la larga, terminaría alcanzando el desarrollo.

Los estudios de la CEPAL demostraron empíricamente que en los hechos eso no ocurre así ya que desde 1870 la tendencia ha sido hacia el permanente deterioro de los términos de intercambio en detrimento de

15 "Como quiera que sea, con su esquema centro-periferia, es decir, al tomar como punto de partida analítico a la economía mundial y las relaciones que allí se desenvuelven entre las economías nacionales, la CEPAL iba mucho más allá de la teoría del desarrollo y aseguraba para el conjunto de sus tesis una validez de principio, hasta entonces privilegio exclusivo de la teoría marxista del imperialismo. De hecho, la afirmación de Prebisch en el sentido de que 'el desarrollo económico de los países periféricos es una etapa más [...] en el proceso de desarrollo orgánico de la economía del mundo' hace recordar irresistiblemente a Bukharin". Marini, op. cit., p. 142 . 
los países exportadores de productos primarios, provocando una constante transferencia de ingreso a favor de los centros.

Al respecto, en la introducción al Estudio Económico de América Latina 1948, Prebisch afirma:

[...] es obvio que los ingresos de los empresarios y factores productivos han crecido, en los centros, más que el aumento de la productividad, y en la periferia, menos que el respectivo aumento de la misma. En otros términos, mientras los centros han retenido íntegramente el fruto del progreso técnico de su industria, los países de la periferia les han traspasado una parte del fruto de su propio progreso técnico. ${ }^{16}$

De acuerdo con Octavio Rodríguez, la explicación del deterioro de los términos de intercambio tuvo en las elaboraciones de la CEPAL tres versiones: la primera aborda el problema desde la falta de elasticidad de la demanda de bienes primarios que lleva a que en los periodos de recesión económica los precios de las materias primas y alimentos tiendan a caer más bruscamente que los bienes industriales y de manera más persistente, deterioro que no se logra resolver con las alzas de precios que se producen en los periodos de bonanza (explicación en versión ciclos); a su vez, en los periodos de recesión la población obrera de los centros, al estar mejor organizada que la de la periferia, ofrece mayor resistencia al deterioro de sus salarios, por lo cual los empresarios hacen recaer los costos de la situación sobre los trabajadores de la periferia mediante los precios de los bienes que exportan (versión contable). En una tercera versión (industrialización) se afirma que la inexistencia en la periferia de un sector industrial limita la oferta de empleos, lo que propicia el aumento de trabajo excedente en los sectores primario y terciario, con efectos negativos en la productividad y en los salarios, todo lo cual deteriora la elevación de la productividad y la expansión del mercado interno.

${ }^{16}$ Raúl Prebisch, "El desarrollo económico de la América Latina y algunas de sus principales problemas", en Cincuenta años..., p. 77. 
No cabe en este trabajo abordar con mayor profundidad las distintas explicaciones que dieron al deterioro de los términos de intercambio Prebisch y su equipo de trabajo, tampoco analizar las limitaciones que se han señalado a las explicaciones cepalinas, ${ }^{17}$ en cambio, debe destacarse que las propuestas teóricas para explicar la tendencia al deterioro de los términos de intercambio abrieron las puertas para avanzar en la reflexión de las especificidades del capitalismo latinoamericano al señalar que en las relaciones comerciales entre naciones existen mecanismos que permiten la transferencia de recursos de la periferia al centro y que esa transferencia se produce porque existen elementos estructurales en el centro y en la periferia que lo permiten, más allá de los factores coyunturales que los precipiten.

Esos planteamientos apuntan la necesidad de estudiar los elementos internos de las economías de América Latina para comprender la naturaleza de esos procesos, es decir, en sí mismos contienen elementos que indican la necesidad de rebasar los límites del análisis centrado en el comercio internacional y de llevarlo al análisis de la estructura y dinámica de las economías que se interrelacionan de manera asimétrica en el comercio internacional; tarea que en cierta medida se iniciaría al interior mismo de la CEPAL durante los primeros años de la década de los sesenta, posibilitando la emergencia del concepto de dependencia.

Cabe mencionar que Ruy Mauro Marini, uno de los principales teóricos marxistas de la dependencia, al referirse a las tesis de la CEPAL sobre el deterioro de los términos de intercambio (y seguramente pensando en su formulación de la sobreexplotación del trabajo) apunta que:

17 Al respecto Marini afirma que "captando correctamente el fenómeno empírico del intercambio, la CEPAL lo interpretaba mal: tarde o temprano el aumento de la productividad y la consiguiente reducción de los costos tienen que transferirse a los precios, salvo si se verifican situaciones anormales en el mercado mundial como las que configuran una situación de monopolio o se derivan de guerras y catástrofes, Además de ello, y la CEPAL no lo ignoraba, el desarrollo del capitalismo en los países dependientes ha implicado, desde el comienzo la introducción de nuevas técnicas de producción y el aumento de la productividad del trabajo", Marini, op. cit., p. 141. 
el señalamiento referente a la cuestión de la remuneración de la fuerza de trabajo representaba una intuición formidable, aunque mal establecida, puesto que no se trataba simplemente de una consecuencia de la baja productividad, como la vida se encargaría de demostrar. ${ }^{18}$

d) La industrialización sustitutiva de importaciones

A partir de la concepción de la economía mundial como un sistema centro-periferia y con base en el estudio de la tendencia al deterioro de los términos de intercambio, la CEPAL formuló sus propuestas para resolver el problema del subdesarrollo latinoamericano, enarboló la idea de la posibilidad de un capitalismo autónomo y la industrialización sustitutiva de importaciones como la vía para lograrlo.

Al ubicar el problema principal del subdesarrollo en la dinámica del comercio internacional, la CEPAL consideró que estableciendo relaciones comerciales internacionales de nuevo tipo sería posible alcanzar un desarrollo capitalista autónomo. Era necesario entonces ganar en la capacidad de decisión y definir rumbos propios. La fórmula consistía, en primer término, en impulsar un importante proceso de industrialización, ello iba a permitir elevar la productividad y retener los frutos del progreso técnico, por la vía de elevar el empleo y de detener las presiones hacia la baja de los salarios y de los precios de las materias primas.

Estos planteamientos, aunados a algunos elementos tomados de la teoría keynesina, llevaron a la CEPAL a postular la necesidad de una activa intervención estatal que, a través de la planeación y haciendo uso de alicientes y desalientos sobre los agentes, permitiera resolver los problemas a los que el libre juego de las fuerzas del mercado no había podido dar solución. La acción estatal debería encaminarse fundamentalmente a promover la industrialización, misma que tendría lugar mediante una política deliberada de sustitución de importaciones de bienes manufacturados, y contaría con toda la protección necesaria por parte del Estado.

${ }^{18}$ Ibid., p. 142. 
Prebisch explica los lineamientos de política económica propuestos por la CEPAL en los siguientes términos:

[...] la sustitución de importaciones estimulada por una política de protección moderada y selectiva es un procedimiento económicamente sensato para el logro de los siguientes efectos deseables: a) Tal política ayudaría a corregir la tendencia hacia una restricción externa del desarrollo, derivada de la baja elasticidad-ingreso de la demanda de importaciones de productos primarios por parte de los centros [...] b) La sustitución de importaciones mediante la protección contrarrestaría la tendencia hacia el deterioro de las condiciones de intercambio al evitar la asignación de recursos productivos adicionales a las actividades de exportación de bienes primarios y desviarlos hacia la producción industrial [...] c) Aparte de su papel en la penetración global del progreso tecnológico y sus efectos sobre el empleo, la industrialización promovería algunos cambios en la estructura de la producción que responden a la elevada elasticidad de la demanda de manufacturas; d) por lo tanto, la industrialización y el aumento de la productividad en la producción primaria son fenómenos complementarios. Cuanto más intenso sea este último, mayor será la necesidad de la industrialización. ${ }^{19}$

En el curso de los años cincuenta el desarrollismo de la CEPAL se convirtió en la ideología dominante y matriz por excelencia de las políticas públicas en América Latina. La posibilidad de un capitalismo autónomo fue una de las grandes utopías a las que se aferró el discurso cepalino original y el aspecto de su pensamiento que refleja con mayor claridad la persistencia de su vínculo con la teoría del desarrollo.

Sin embargo, tras una década de expansión, las economías latinoamericanas iniciaron en los años sesenta, un periodo de relativo estancamiento que puso al desnudo los problemas y contradicciones generados por la estrategia de industrialización sustitutiva. El crecimiento económico de la mayoría de los países, pese a ser persistente, se daba en medio de una creciente inestabilidad macroeconómica, motivada en buena

${ }^{19}$ Prebisch, "Cinco etapas...", p. 347. 
medida por las restricciones a las importaciones, que dieron lugar a un significativo aumento de la inflación. El proceso de industrialización seguía adelante, pero la urbanización consiguiente se traducía en empobrecimiento creciente de la población rural y en la proliferación de "ciudades perdidas" en las zonas urbanas, síntomas de la incapacidad de absorción de la fuerza trabajadora proveniente de la zona rural por las actividades productivas industriales, suscitando una inconformidad creciente y movilizaciones sindicales y campesinas.

Asimismo, el triunfo de la Revolución cubana en 1959 modificó la actitud norteamericana hacia los países latinoamericanos, buscando, a través de la Alianza para el Progreso, programa dirigido por la Organización de los Estados Americanos, prevenir cualquier movimiento que pudiera desembocar en una nueva revolución en América Latina.

Al iniciarse la década de los sesenta la nueva problemática llevó a la CEPAL a reorientar sus trabajos a fin de incluir en sus estudios aportes de carácter sociológico, y a iniciar un proceso de revisión de las concepciones que se habían gestado hasta entonces.

Con relación a la inclusión de los análisis sociológicos deben destacarse los aportes de José Medina Echavarría cuya preocupación central en aquella época era compatibilizar el desarrollo económico con los problemas sociales de América Latina. Medina Echavarría basaba en buena medida sus estudios en la teoría del desarrollo (más que en la formulación cepalina del subdesarrollo) con miras a crear una perspectiva sociológica del desarrollo latinoamericano, ${ }^{20}$ y así destacó nuevamente desde esa perspectiva la necesidad de encontrar caminos propios que no se limitaran a repetir los esquemas impulsados por las economías centrales.

Las problemáticas a las que tenían que hacer frente los países latinoamericanos llevaron entonces a la revisión y reformulación de la con-

${ }^{20}$ Los planteamientos de Medina Echavarría en esa dirección se encuentran en su libro Consideraciones sociológicas sobre el desarrollo económico en América Latina, publicado en 1963 . 
cepción originaria y de las políticas que de ella se derivaron al interior mismo de la CEPAL, abriendo un nuevo periodo de discusión y producción teórica de gran riqueza tendiente a fundamentar las necesarias reformas para dinamizar la economía y a explicar los problemas surgidos en la región durante los años sesenta. De los aportes que trajo consigo ese periodo de revisión crítica del proceso de desarrollo en curso lo más importante en lo que a este trabajo se refiere, fue que en ellos empezó a emerger y a cobrar fuerza el concepto de dependencia.

\section{LA CRISIS DEL DESARROLLISMO Y LA EMERGENCIA DEL CONCEPTO DE DEPENDENCIA}

Los últimos años de la década de los sesenta y los primeros de la siguiente fueron para América Latina años de crisis económica y política. El patrón de acumulación y los lineamientos de política económica impulsados desde la CEPAL — que buscaban resolver el problema del subdesarrollo latinoamericano a través de la industrialización sustitutiva de importaciones - mostraban claros signos de agotamiento. Si bien se había registrado un importante proceso de industrialización en muchos de los países de la región, empezaba a evidenciarse la incapacidad de financiar la industrialización sustitutiva con recursos propios, con el consecuente incremento del endeudamiento externo.

Paralelamente, las contradicciones al interior de las clases y grupos gobernantes en torno a la forma de garantizar la reproducción de capital y la necesidad de la burguesía de evitar un nuevo estallido revolucionario en América Latina, condujeron a la imposición de regímenes más represivos en casi todos los países, en algunos casos mediante golpes militares, como en Brasil (1964) y Argentina (1966).

El agotamiento del patrón de acumulación sustitutivo de importaciones y la agudización de la lucha de clases, marcó la crisis del pensamiento desarrollista emanado de la CEPAL, en tanto que proyecto alternativo para el desarrollo de nuestros países. Sin embargo, en el plano 
teórico, los horizontes de reflexión que abrieron las formulaciones teóricas del desarrollismo posibilitaron, a la luz de nuevas investigaciones empíricas, avanzar en la construcción de nuevos conceptos, especialmente el de dependencia, para estudiar la realidad latinoamericana.

El concepto de dependencia surge en América Latina como resultado del proceso de discusión sobre el tema del subdesarrollo y el desarrollo. En la medida en que no se cumplen las expectativas puestas en los efectos de la industrialización, se pone en duda la teoría del desarrollo que sirve de base al modelo de desarrollo nacional e independiente elaborado en los años 50. El concepto que sirve de camino para la superación de los errores anteriores es el de dependencia. ${ }^{21}$

El punto de partida para la construcción de la dependencia como categoría explicativa, fue la ruptura con la idea de que la dependencia era un factor externo que podría resolverse en la medida que se avanzara en el proceso de industrialización y se estableciera una dinámica diferente en los términos de intercambio del mercado internacional, dando paso a la posibilidad de un desarrollo capitalista autónomo para los países latinoamericanos.

Diversas investigaciones empíricas, muchas de ellas realizadas en el interior mismo de la CEPAL o en organismos dependientes de ésta, mostraron que la industrialización sustitutiva no traía las consecuencias esperadas por la visión desarrollista. La industrialización, que debiera representar una mayor autonomía de decisión para los países latinoamericanos, pasaba a ser comandada por la inversión externa, fundada en la empresa multinacional, cuyo centro de poder continuaba en los polos centrales de la economía mundial. Asimismo, la mayoría de los países de la región comenzaban a experimentar un estancamiento relativo y la idea de que el simple proceso de industrialización transformaría la

${ }^{21}$ Theotonio Dos Santos, Imperialismo y dependencia, $4^{a}$. ed., México, Era, 1986, p. 300 . 
estructura social y política latinoamericana creando sociedades similares a las de los países desarrollados, recibió un mentís definitivo con el incremento del desempleo; con los grandes contingentes de mano de obra que la industria desplazaba a las ciudades y que no podían ser absorbidos por ésta; con el surgimiento por doquier de "ciudades perdidas" y "cinturones de miseria"; con la cada vez más crítica situación de los campesinos y, especialmente, con las luchas sociales que se hacían sentir fuertemente a lo largo y ancho de la región.

Frente a estas problemáticas y al seguir el esquema centro-periferia algunos autores, como Osvaldo Sunkel y Pedro Paz, expusieron la tesis de que el desarrollo y el subdesarrollo constituyen dos caras de un mismo proceso, desechando la idea de que el subdesarrollo constituye un peldaño más bajo en la escala del desarrollo. Sin embargo, el peso de los factores externos prosigue captando la atención fundamental en la explicación del subdesarrollo, incorporando el concepto de dependencia para aludir a la dependencia externa que impide alcanzar el desarrollo autónomo.

Entre los trabajos que circularon en aquellos años, destaca el del brasileño Fernando Henrique Cardoso y el chileno Enzo Faletto titulado Dependencia y desarrollo en América Latina ${ }^{22}$ que expresa el mayor avance de las rupturas que se produjeron dentro de la CEPAL con sus formulaciones originales y constituye una importante aproximación, desde la radicalización del desarrollismo, a la formulación de la dependencia como categoría para el análisis de América Latina.

Después de una rápida revisión de los principales problemas que se presentaban en América Latina en los primeros años de la década de los sesenta y de apuntar que el esquema interpretativo y las previsiones, que se habían formulado al iniciar la década anterior, resultaron insuficientes para explicar el curso posterior de los acontecimientos, Cardoso y Faletto, señalan:

${ }^{22}$ El libro fue publicado por primera vez en 1969, pero circuló como material interno del Instituto Latinoamericano de Planificación Económica y Social (ILPES), organismo dependiente de la CEPAL. 
no es suficiente reemplazar la interpretación "económica" del desarrollo por un análisis "sociológico". Falta un análisis integrado que otorgue elementos para dar respuesta en forma más amplia y matizada a las interrogantes generales sobre las posibilidades del desarrollo o estancamiento de los países latinoamericanos, y que responda a las preguntas decisivas sobre su sentido y sus condiciones políticas y sociales. ${ }^{23}$

Al apoyarse en ello y combinar elementos de la teoría weberiana y marxista, Cardoso y Faletto formularon su propuesta de un análisis integrado del desarrollo. Con base en una crítica a la teoría del desarrollo, que es, en cierta medida, también una crítica al esquema centro-periferia, señalan que el análisis tipológico basado en los conceptos "sociedad tradicional" y "sociedad moderna", del que se ha derivado la noción de que en el curso del proceso de cambio social existe una forma intermedia que caracteriza a las sociedades "en desarrollo", no permite abarcar en forma precisa todas las situaciones sociales existentes, ni permite distinguir entre ellas los componentes estructurales que definen el modo de ser de las sociedades analizadas. Destacan que desde esa perspectiva no se toma en cuenta que:

[...] el cambio de las estructuras sociales, lejos de ser sólo un proceso acumulativo en el cual se agregan nuevas "variables" que se incorporan a la configuración estructural, implica fundamentalmente un proceso de relaciones entre grupos, fuerzas y clases sociales a través de la cual algunos de ellos intentan imponer al conjunto de la sociedad la forma de dominación que les es propia. ${ }^{24}$

Cardoso y Faletto señalan asimismo, que tomar como punto de partida los conceptos "sociedad tradicional" y "sociedad moderna" y bus-

${ }^{23}$ F. H. Cardoso y Enzo Faletto, Dependencia y desarrollo en América Latina, $23^{\mathrm{a}}$ ed., México, Siglo XXI, 1998, p. 10. Las citas están tomadas de esta edición del texto de Cardoso y Faletto presenta algunas diferencias (sobre todo de redacción) con el texto que se publicó en 1969. Esas modificaciones fueron introducidas por los autores para la decimocuarta edición, publicada en 1978.

${ }^{24}$ Ibid., p. 13. 
car crear una especie de puente entre ellas siguiendo las pautas de los sistemas político, social y económico de los países de Europa occidental y Estados Unidos (lo que se ha dado en llamar "efecto de demostración") es lo que ha llevado a ponderar el aspecto económico como lo fundamental y a considerar que el dinamismo de las sociedades subdesarrolladas deriva de factores externos. Para superar estas limitaciones, afirman los autores, es necesaria una perspectiva diferente que permita establecer las relaciones (económicas y sociales) que hacen inteligibles las situaciones empíricas en función del modo de conexión entre los componentes estructurales internos y externos.

Para el análisis global del desarrollo no es suficiente, [...] agregar al conocimiento de los condicionantes estructurales, la comprensión de los "factores sociales", entendidos éstos como nuevas variables de tipo estructural. Para adquirir significación, tal análisis requiere un doble esfuerzo de redefinición de perspectivas: por un lado, considerar en su totalidad las "condiciones históricas particulares" - económicas y sociales - subyacentes en los procesos de desarrollo, en el plano nacional y en el plano externo; por otro, comprender, en las situaciones estructurales dadas, los objetivos e intereses que dan sentido, orientan o alientan el conflicto entre los grupos y clases y los movimientos sociales que "ponen en marcha" las sociedades en desarrollo. [...] Se trata, por consiguiente, de buscar una perspectiva que permita vincular concretamente los componentes económicos y sociales del desarrollo en el análisis de la actuación de los grupos sociales, no sólo de yuxtaponerlos. Ello supone que el análisis sobrepase el aporte de lo que suele llamarse enfoque estructural, reintegrándolo en una interpretación hecha en términos de "proceso histórico". ${ }^{25}$

La perspectiva de análisis integrado del desarrollo propuesta por Cardoso y Faletto implica un rompimiento epistemo-metodológico con la concepción cepalina original, en tanto que se propone superar la concepción de la historia como proceso lineal acumulativo (que de acuerdo con los autores subyace en la teoría del desarrollo y en las primeras ela-

${ }^{25}$ Ibid., p. 17. 
boraciones cepalinas) y concebir la historia de América Latina como un proceso de relaciones que deben ser consideradas en su totalidad. Es en función de ello que cobra importancia para Cardoso y Faletto el concepto de dependencia, con el cual, afirman:

se pretende otorgar significado a una serie de hechos y situaciones que aparecen conjuntamente en un momento dado y se busca establecer por su intermedio las relaciones que hacen inteligibles las situaciones empíricas en función del modo de conexión entre los componentes estructurales internos y externos. ${ }^{26}$

El reconocimiento de la historicidad de la situación de subdesarrollo, afirman los autores, requiere ir más allá que el señalamiento de las características estructurales de las economías subdesarrolladas; es indispensable analizar cómo éstas se vincularon históricamente al mercado mundial y la forma en que se constituyeron los grupos sociales internos responsables de definir las relaciones hacia afuera que el subdesarrollo supone.

Tal enfoque implica reconocer que en el plano político-social existe algún tipo de dependencia en las situaciones de subdesarrollo, y que esa dependencia empezó históricamente con la expansión de las economías de los países capitalistas originarios. ${ }^{27}$

Según los investigadores, el objetivo del análisis integrado es comprender la formación de economías nacionales, por lo cual no se puede discutir con precisión el proceso de desarrollo desde un ángulo puramente económico.

[...] la "situación de dependencia" en el análisis del desarrollo latinoamericano, lo que se pretende poner de manifiesto es que el modo de integración de las economías nacionales al mercado internacional supone formas

${ }^{26}$ Ibid., p. 20.

${ }^{27}$ Ibid., p. 24. 
definidas y distintas de interrelación de los grupos sociales de cada país, entre sí y con los grupos externos. [...] los influjos del mercado, por sí mismos, no son suficientes para garantizar su continuidad o su dirección, la actuación de las fuerzas, grupos e instituciones sociales pasa a ser decisiva para el análisis del desarrollo. ${ }^{28}$

En la formulación propuesta por Cardoso y Faletto, el concepto de dependencia intenta advertir, fundamentalmente, sobre la existencia de una forma de dominación que define la actuación y orientación de los grupos sociales en los países periféricos.

La dependencia de la situación de subdesarrollo implica socialmente una forma de dominación que se manifiesta por una serie de características en el modo de actuación y en la orientación de los grupos que en el sistema económico aparecen como productores o como consumidores. Situación que supone, en los casos extremos que las decisiones que afectan a la producción o al consumo de una economía dada se toman en función de la dinámica y los intereses de las economías desarrolladas. ${ }^{29}$

Hasta entonces uno de los rasgos más notorios de las elaboraciones teóricas cepalinas, lo constituía el énfasis en los elementos económicos como aspectos explicativos del subdesarrollo, pero desligaban su estudio de las clases sociales y su gestión limitándose a la consideración de las variables técnicas del atraso y los desequilibrios, Cardoso y Faletto enfrentaron esta situación, otorgando al análisis de las clases y sus alianzas mayor importancia. Sin embargo, en su propuesta metodológica prevalece la separación entre "lo económico" y "lo social", con lo que, de acuerdo con Vania Bambirra, lo económico está presente sólo como un marco muy general, a partir del cual se desarrolla un análisis esencialmente sociológico, desde una perspectiva weberiana; el estudio se centra en "la acción de los distintos grupos", pero en la medida en que lo

${ }^{28}$ Ibid., p. 28.

${ }^{29}$ Ibid., p. 24. 
económico importa sólo en cuanto define los patrones estructurales, no permite revelar en toda su complejidad la gama intrincada de la acción de los diversos grupos y clases sociales que actúan en función de intereses económicos objetivos, cuya imposición exige la lucha por la hegemonía política. ${ }^{30}$

Con la obra de Cardoso y Faletto, la dependencia fue incluida en el marco conceptual desarrollado en el seno de la CEPAL, buscando incorporar cierta noción de dominación, la imbricación de los factores económicos y sociales y la consideración de los elementos externos e internos; sin embargo, no alcanzó mayor desarrollo al interior del organismo.

\section{DEPENDENCIA Y MARXISMO}

En aquellos años, alentada por el triunfo de la Revolución cubana fue tomando fuerza en América Latina una corriente marxista que teniendo como punto de partida la crítica al desarrollismo, construyó una perspectiva propia en torno a la dependencia e impulsó una contrapropuesta a la concepción del marxismo ortodoxo que leía la realidad latinoamericana desde supuestos principios rectores de esa teoría, válidos para todo tiempo y lugar.

En la lucha contra el desarrollismo la teoría de la dependencia había sido también una lucha contra las viejas ideas de los partidos comunistas que veían América Latina como una zona colonial o semicolonial, feudal, en que era necesario hacer la revolución burguesa a fin de crear las condiciones para la superación de la explotación imperialista. Planteaban, por lo tanto la idea de la revolución antifeudal, antiimperialista y democrática. Y en ese sentido cruzaban bien, si se ve bien, se articulaban bien, se combinaban bien con lo que planteaba la burguesía industrial a través del desarrollismo, a través de la tesis del dualismo estructural, del desarrollo

${ }^{30}$ Véase Vania Bambirra, El capitalismo dependiente latinoamericano, México, Siglo XXI, 1974. 
endógeno como un factor capaz de llevar a nuevas estructuras sociales y políticas superiores, etcétera. ${ }^{31}$

La reflexión desarrollada en torno a la dependencia por esta corriente marxista no partió de cero, se apoyó tanto en el horizonte de visibilidad abierto por el pensamiento cepalino, como en diversos trabajos que se habían realizado en años previos y que tenían como denominador común negar el carácter feudal de la formación social latinoamericana. En ese sentido fue de especial importancia el libro de Sergio Bagú, Economía de la sociedad colonial: ensayo de historia comparada de América Latina, publicado en Buenos Aires en 1949; así como el trabajo de Luis Vitale, América Latina: ¿feudal o capitalista?, publicado en 1966; y el ensayo de Rodolfo Stavenhagen, "Siete Tesis erróneas sobre América Latina", publicado en junio de 1965 en el periódico mexicano El Día.

Otro trabajo que contribuyó significativamente en el plano teórico para avanzar en la construcción de la dependencia como instrumento analítico desde la perspectiva marxista fue el ensayo de André Gunder Frank, El desarrollo del subdesarrollo capitalista en Chile, ${ }^{32}$ en el que el autor presenta una de las más profundas y conocidas críticas al pensamiento desarrollista. El trabajo de Frank y las fuertes discusiones que suscitó en el medio académico, constituyeron un parteaguas fundamental en la ubicación del problema del subdesarrollo como un fenómeno inscrito en los movimientos de la economía internacional, en la ruptura con la idea del subdesarrollo como una etapa anterior al desarrollo y con las ilusiones de un capitalismo autónomo, alimentadas por las teorías de la modernización y el desarrollismo.

31 Adrián Sotelo Valencia, "Entrevista a Ruy Mauro Marini: Las perspectivas de la teoría de la dependencia en la década de los noventa", Estudios Latinoamericanos, núm. 9, julio-diciembre, 1990, FCPys/UNAM, p. 55.

${ }^{32} \mathrm{El}$ ensayo fue publicado posteriormente en el libro Capitalismo y subdesarrollo en América Latina, Siglo XXI Editores, Buenos Aires, 1970. 
Apoyado más en geniales intuiciones que en un bagaje teórico riguroso, el trabajo de Frank apuntó a problemas claves y a líneas políticas correctas. Así por ejemplo, su hasta hoy válida fórmula del "desarrollo del subdesarrollo" sintetizaba agudamente la profundización de los desequilibrios y los atrasos de América Latina respecto a las economías industriales en tanto se siguiera una vía capitalista de desarrollo, pero al extender históricamente la situación de dependencia en América Latina confundía a ésta con la situación colonial. ${ }^{33}$

A partir de la tesis de Frank el problema del desarrollo de los países latinoamericanos empezó a plantearse en otros términos. No era simplemente que el desarrollo fuera posible o no, sino que, de acuerdo con la evidencia empírica, el desarrollo capitalista en América Latina mostraba ser un factor que profundiza y agrava las condiciones de dependencia.

Esta idea suscitó confusiones en el sentido de que fue interpretada como una negación a toda posibilidad de desarrollo para los países latinoamericanos. Sin embargo, el planteamiento hacía referencia a las posibilidades de desarrollo en el marco del sistema capitalista, haciendo hincapié en que la evidencia empírica mostraba que a más desarrollo, más dependencia.

No se está negando, en absoluto, el desarrollo capitalista en los países dependientes. Se está afirmando que el desarrollo capitalista de esos países simplemente significa, se traduce, en profundización de la dependencia con lo que ella implica en materia de explotación, de miseria y opresión de las masas. ${ }^{34}$

Visto el problema de esta manera, fue profundizándose en la idea de que el subdesarrollo no es una etapa, ni un movimiento de tránsito hacia el desarrollo, sino al contrario, es la contraparte de lo que genera permanentemente el desarrollo. Es decir, el subdesarrollo latinoameri-

33 Jaime Osorio, "El marxismo latinoamericano y la dependencia", Revista Cuadernos Políticos, núm. 39, México, enero-marzo, 1984, p. 45.

34 Sotelo, op. cit., p. 53. 
cano es la contrapartida necesaria del desarrollo capitalista en los grandes centros. Y esto se debe no sólo a factores externos, sino a una dinámica que configura también cierto tipo de estructuras internas.

Con estos planteamientos el tema de las particularidades del capitalismo periférico o dependiente se convirtió en el punto central de discusión y el concepto de dependencia posibilitó un giro en el análisis hacia el interior de las economías latinoamericanas, en el marco de la expansión del capitalismo y del desarrollo del sistema económico mundial.

Enfocar la dependencia como una condición que configura cierto tipo de estructuras internas, significa tomar el desarrollo como un fenómeno histórico mundial: como resultado de la formación, expansión y consolidación del sistema capitalista. Tal perspectiva implica la necesidad de integrar, en una sola historia, la perspectiva de la expansión capitalista en los países hoy desarrollados y sus resultados en los países por él afectados. Pero no se trata de tomar estos resultados como simples "efectos" del desarrollo capitalista, sino como su parte integrante y determinante. ${ }^{35}$

En su libro Subdesarrollo y Revolución, Ruy Mauro Marini, plantea esta misma idea como premisa fundamental para el estudio de la realidad latinoamericana:

La historia del subdesarrollo latinoamericano es la historia del desarrollo del sistema capitalista mundial. Su estudio es indispensable para quien desee comprender la situación a la que se enfrenta actualmente este sistema y las perspectivas que se le abren. Inversamente, sólo la comprensión segura de la evolución de los mecanismos que caracterizan a la economía capitalista mundial proporciona el marco adecuado para ubicar y analizar la problemática de América Latina. ${ }^{36}$

De acuerdo con Ruy Mauro Marini, en la medida en que la crítica al desarrollismo fue profundizándose, se hizo necesario incorporar al aná-

35 Dos Santos, Imperialismo..., p. 301.

${ }^{36}$ Ruy Mauro Marini, Subdesarrollo y Revolución, $5^{\text {a }}$ ed., México, Siglo XXI, 1974, p. 3. 
lisis del desarrollo del capitalismo latinoamericano elementos de la economía política marxista y de la teoría leninista del imperialismo, buscando ampliar la capacidad explicativa de la dependencia como categoría de análisis.

La teoría de la dependencia se va a valer de instrumentos que va tomando del marxismo para criticar a la teoría desarrollista. Una cuestión importante es que la teoría desarrollista, aunque sin proponérselo, dio elementos para orientar el pensamiento de la dependencia en esa dirección. Sin embargo, el elemento más importante fue la teoría del imperialismo, la teoría leninista del imperialismo, la que realmente constituyó un elemento, ya de partida, en el pensamiento de la dependencia. ${ }^{37}$

Uno de los autores que más impulsó en el plano teórico y metodológico la construcción de la dependencia como instrumento analítico fue el brasileño Theotonio Dos Santos, sus críticas a la teoría del desarrollo y sus formulaciones sobre las diversas "formas de dependencia", permitieron mostrar que el estudio de esta problemática era un campo indispensable para explicar la realidad latinoamericana. Su libro Imperialismo y dependencia, publicado por primera vez en 1978, recoge buena parte de los mejores trabajos desarrollados en años anteriores y avanza, principalmente, en el estudio de la dependencia en el marco del imperialismo.

A pesar de que la dependencia, debe ser situada en el cuadro global de la teoría del imperialismo, tiene su realidad propia que constituye una legalidad específica dentro del proceso global y que actúa sobre él de esta manera específica. Comprender la dependencia, conceptuándola y estudiando sus mecanismos y su legalidad histórica, significa no sólo ampliar la teoría del imperialismo sino también contribuir a su mejoría y reformulación. ${ }^{38}$

37 Sotelo, op. cit., p. 53.

${ }^{38}$ Dos Santos, Imperialismo..., p. 302. 
En ese mismo libro Theotonio Dos Santos presenta una definición del concepto de dependencia, en la que ésta es concebida como una situación condicionante que determina los límites posibles del desarrollo de los países latinoamericanos y sus formas. Definición en la que profundizaré más adelante para descubrir las posibilidades que ofrece como instrumento analítico.

Por su parte Ruy Mauro Marini, sociólogo, brasileño también, señala que la dependencia debe ser entendida no como una condición de los países latinoamericanos sino como:

[...] una relación de subordinación entre naciones formalmente independientes, en cuyo marco las relaciones de producción de las naciones subordinadas son modificadas o recreadas para asegurar la reproducción ampliada de la dependencia. ${ }^{39}$

Fue precisamente Ruy Mauro Marini quien apoyándose en una serie de trabajos empíricos y análisis de procesos específicos, elaboró una explicación teórica global de la dependencia latinoamericana desde una perspectiva marxista.

Curiosamente y como una prueba más de las debilidades de los economistas marxistas latinoamericanos, va a ser un sociólogo - Ruy Mauro Marini- el que formulará las bases de la economía política de la dependencia, marcando con su libro Dialéctica de la dependencia el corte en el proceso de transición de una categoría que, surgida en un campo teórico ajeno al marxismo, asume un estatuto teórico marxista. En Dialéctica de la dependencia, el marxismo latinoamericano alcanza su punto más alto en tanto formulación de las leyes y tendencia que engendran y mueven el capitalismo sui géneris llamado capitalismo dependiente. Esto se alcanza luego de una década de estudios sobre el tema. ${ }^{40}$

La propuesta teórica planteada por Marini implica una postura epistemo-metodológica que recoge las posibilidades analíticas que se

${ }^{39}$ Ruy Mauro Marini, Dialéctica de la Dependencia, $3^{\mathrm{a}}$ ed., México, Era, p. 18.

${ }^{40}$ Osorio, "El marxismo..., p. 46. 
fueron abriendo durante el periodo de intensa elaboración y discusión teórica iniciado por la CEPAL y que constituyeron un hilo conductor del pensamiento latinoamericano hasta el inicio de la década de los ochenta.

Hilo conductor que inicia esencialmente con la visión de América Latina como un problema teórico y que, pasando por el esquema centroperiferia, la tesis del deterioro de los términos de intercambio y la propuesta de la industrialización sustitutiva de importaciones, desembocó, tras una serie de rupturas teóricas y metodológicas, en la construcción de la dependencia como categoría de análisis. Instrumento analítico que es una conquista del pensamiento social latinoamericano ya que posibilita pensar los problemas específicos de América Latina en el cuadro de la expansión del capitalismo y del desarrollo del sistema económico mundial, integrando lo político con lo económico y con lo social, en la búsqueda de alternativas para los pueblos latinoamericanos.

\section{BIBLIOGRAFÍA}

BAMBIRRA, Vania, El capitalismo dependiente latinoamericano, México, Siglo XXI, 1974, $180 \mathrm{pp}$.

BIELSCHOWSKY, Ricardo, "Cincuenta años del pensamiento de la CEPAL: una reseña", en Cincuenta años del pensamiento en la CEPAL. Textos seleccionados, Santiago de Chile, CEPAL/FCE, 1998, pp. 9-61.

CARdoso, F. H. y Enzo Faletto, Dependencia y desarrollo en América Latina, $23^{a}$ ed., México, Siglo XXI, 1988, 213 pp.

Dos SAntos, Theotonio, Imperialismo y dependencia, $4^{\mathrm{a}}$ ed., México, ERA, 1986, $471 \mathrm{pp}$.

, La teoría de la dependencia. Balance y perspectivas, México, Plaza y Janés, 2002, 148 pp.

"La teoría de la dependencia. Un balance histórico y teórico", en Los retos de la globalización. Ensayos en homenaje a Theotonio Dos Santos, Caracas, UNESCO, 1998.

ESTAY ReINO, Jaime, "La concepción inicial de Raúl Prebisch y sus transformaciones", en Ruy Mauro Marini y Márgara Millán [coords.], La teoría social latinoamericana. T. II Subdesarrollo y Dependencia, México, Ediciones el Caballito, 1994, pp. 17-40. 
FuRTADO, Celso, "Desarrollo y subdesarrollo", en Cincuenta años del pensamiento en la CEPAL. Textos seleccionados, Santiago de Chile, CEPAL/FCE, 1998, pp. 229-242.

MARINI, Ruy Mauro, Dialéctica de la Dependencia, $3^{\text {a }}$ ed., México, Era, 1977, 101 pp. (Serie Popular).

, "La crisis del desarrollismo", en Ruy Mauro Marini y Márgara Millán [coords.], La teoría social latinoamericana. T. II Subdesarrollo y Dependencia, México, Ediciones El Caballito, 1994, pp. 135-154.

, Subdesarrollo y Revolución, 5ª ed., México, Siglo XXI, 1974, 204 pp.

OsORIO, Jaime, "Actualidad de la reflexión sobre el subdesarrollo y la dependencia: una visión crítica”, en Ruy Mauro Marini y Márgara Millán [coords.], La teoría social latinoamericana, T. IV Cuestiones contemporáneas, México, UNAM/Ediciones El Caballito, 1996, pp. 25-46.

, "El marxismo latinoamericano y la dependencia", Revista Cuadernos Políticos, núm. 39, México, enero-marzo, 1984, pp. 40-59.

, "Fuentes y tendencias de la teoría de la dependencia", en Ruy Mauro Marini y Márgara Millán [coords.], La teoría social latinoamericana. T. II Subdesarrollo y Dependencia, México, Ediciones El Caballito, 1994, pp. 157-178.

,Fundamentos del análisis social. La realidad social y su conocimiento, México, UAM/FCE, 2001, 174 pp.

Prebisch, Raúl, "Cinco etapas de mi pensamiento sobre el desarrollo", Comercio Exterior, vol. 37, núm. 5, México, mayo, 1987, pp. 345-352.

" "El desarrollo económico de la América Latina y algunos de sus principales problemas", en Cincuenta años del pensamiento en la CEPAL. Textos seleccionados, Santiago de Chile, CEPAL/FCE, 1998, pp. 63-130.

RoDRíGUEZ, Octavio, La teoría del subdesarrollo del la CEPAL, México, Siglo XXI, 1980, 298 pp.

Sotelo VAlENCIA, Adrián, "Entrevista a Ruy Mauro Marini: Las perspectivas de la teoría de la dependencia en la década de los noventa", Estudios Latinoamericanos, núm. 9, julio-diciembre, 1990, FCPyS-UNAM, pp. 49-58. 